\title{
THE ROLE OF SOCIAL SUPPORT IN ADULT WOMEN'S WEIGHT LOSS: A
} LITERATURE REVIEW.

EL PAPEL DEL APOYO SOCIAL EN LA PÉRDIDA DE PESO DE LAS MUJERES ADULTAS: UNA REVISIÓN DE LA LITERATURA.

Martínez Jaikel Tatiana*

*Escuela de Nutrición, Universidad de Costa Rica.

Citation: Martínez Jaikel T. (2019) The role of social support in adult women's weight loss: A literature review. Revista Salud Pública y Nutrición, $18(3), 38-44$.

Editor: Esteban G. Ramos Peña, Dr. CS., Universidad Autónoma de Nuevo León, Facultad de Salud Pública y Nutrición, Monterrey Nuevo León, México. Copyright: (C2019 Martínez Jaikel T. et al. This is an open-access article distributed under the terms of Creative Commons Attribution License [CC BY 4.0], which permits unrestricted use, distribution, and reproduction in any medium, provided the original author and source are credited.

Competing interests: The authors have declared that no competing interests exist.

DOI: https://doi.org/10.29105/respyn18.3-4

Recibido: 09 de abril 2019; Aceptado: 26 de julio 2019

Email: tatimartinez@hotmail.com 


\title{
THE ROLE OF SOCIAL SUPPORT IN ADULT WOMEN'S WEIGHT LOSS: A LITERATURE REVIEW.
}

\author{
Martínez Jaikel Tatiana*. \\ *Escuela de Nutrición, Universidad de Costa Rica.
}

\begin{abstract}
Introduction: Excess body weight is a worldwide health problem. Social support may play a central role during weight loss processes; however, this relationship has not been clearly established. Objective: To determine the role of social support in adult women's weight loss. Material and method: We conducted a systematic review searching four databases: PubMed, Ebsco Medline with full text, PsycINFO and Web of Science. The articles reviewed were 1) related to at least one of the research questions; 2) showed intervention studies aiming to evaluate the effectiveness of the familiar social support component in weight loss; 3 ) included adult women between 18 and 65 years old in the population of the study. Results: Ten studies relating family social support to weight loss: only a few of them have shown an association between weight loss and family social support, and none of the studies found an association between family social support and BMI; involving family members in weight loss programs seems to have some positive effects but the results are mixed. Limitations: Studies used different definitions and measures to evaluate family social support; some of them were excluded because they did not differentiate in their analysis between men and women. Conclusions: There seems to be a positive effect between social support and weight loss in women, but more studies are necessary to draw solid conclusions.

Key words: Family social support- weight loss-women

\section{RESUMEN}

Introducción. El exceso de peso corporal, es un problema de salud mundial. El apoyo social podría jugar un papel central durante los procesos de pérdida de peso, sin embargo, esta relación no está claramente establecida. Objetivo: Determinar el papel del apoyo social en la pérdida de peso de las mujeres adultas. Material y método: Realizamos una revisión sistemática buscando cuatro bases de datos: PubMed, Ebsco Medline con texto completo, PsycINFO y Web of Science; e incluyendo artículos que fueron 1) relacionados con al menos una de las preguntas de investigación; 2) estudios de intervención con el objetivo de evaluar la efectividad del componente de apoyo social familiar en la pérdida de peso; 3) la población del estudio eran mujeres adultas entre 18 y 65 años. Resultados: Se encontraron diez estudios que relacionan el apoyo social familiar con la pérdida de peso: solo algunos de ellos demostraron una asociación entre la pérdida de peso y el apoyo social familiar, y ninguno encontró una asociación entre el apoyo social familiar y IMC; involucrar a miembros de la familia en programas de pérdida de peso parece tener algún efecto positivo pero los resultados fueron mixtos. Limitaciones: los estudios utilizaron diferentes definiciones y medidas para evaluar el apoyo social familiar; algunos de ellos fueron excluidos porque no diferenciaron en su análisis entre hombres y mujeres. Conclusiones: Parece existir un efecto positivo entre el apoyo social y la pérdida de peso en las mujeres, pero se necesitan más estudios para establecer conclusiones sólidas.

Palabras Clave: Apoyo social familiar, pérdida de peso, mujeres.
\end{abstract}




\section{Introduction}

Overweight and obesity, as defined as excess body weight, are a worldwide health problem, including Latin-American countries (World Health Organization, 2015). For example, in Mexico, according to data from the Encuesta Nacional de Salud y Nutrición de Medio Camino 2016, more than $70 \%$ of adults are considered to be overweight or obese. Specifically, in Mexican adult women, in 2016 the prevalence of excess body weight (BMI $\geq 25$ ) was $72.7 \%$ (Secretaría de Salud, 2017). Excess body weight is associated with the leading causes of death worldwide, such as cardiovascular disease, stroke, diabetes, and some types of cancer (Center for Disease Control and Prevention, 2018; NHLBI Obesity Education Initiative Expert Panel, 1998; World Health Organization, 2015). Other psychosocial consequences such as depression, insecurity, isolation, and lack of self-esteem are also documented more often in women (Azarbad \& Gonder-Frederick, 2010; Luppino et al., 2010). For this reason, the prevention and treatment of excess body weight is fundamental to maintain population health. Excess body weight results from multiple causes and contributing factors, including individual and environment factors, therefore its treatment should involve multiple interventions and strategies (CDC, 2018; NIDDK, 2012; NHLBI Obesity Education Initiative Expert Panel, 1998).

Promoting a healthy diet and exercise are two of the most important components of weight loss interventions (NHLBI Obesity Education Initiative Expert Panel, 1998) and for both, a behavior change is required. Theoretically, social support may play a central role during weight loss processes (Greaves et al., 2011; Verheijden, Bakx, van Weel, Koelen, \& van Staveren, 2005).

The concept of social support has been used to define many different concepts, such as emotional, instrumental, informational, and appraisal support (Thoits, 2011; Verheijden et al., 2005). Uchino (2009) differentiates between perceived and received social support. He points out that this is a main distinction because perceived support has had a greater relationship to health in a more consistent way than received support has. Perceived support is related to one's potential access to social support. On the other hand, received support is more a relational factor that appears during a specific time frame and usually in response to stressful circumstances (Uchino, 2009).

Family, as a primary group, is one of the most recognized sources of social support (Thoits, 2011). In women, who are used to undertaking most of the domestic and care work in Latin American countries (Economic Commission for Latin America and the Caribbean, 2018), having the support of their family members may be crucial to implement healthier food and physical activity behaviors. For example, in our study in Costa Rica conducted with food- insecure, excess-weight women, we found that family may help in the efforts to lose weight or may hinder it. Some of the problems that women face when they are trying to lose weight are that family members do not want to eat healthily. Also, the family, and especially their partners, tries to "boycott" their intentions to lose weight by bringing home foods high in calories and fat (Martinez-Jaikel \& Frongillo, 2016). Therefore, to recognize the main role that family members play in weight loss processes has strong rationality.

Some literature reviews have evaluated the effect of the family members in adult weight loss, the results tend to show positive results, however the evidence is not fully consistent (Avenell et al., 2004; Black, Gleser, \& Kooyers, 1990; Glenny, O'Meara, Melville, Sheldon, \& Wilson, 1997; Kelsey, Earp, \& Kirkley, 1997; McLean, Griffin, Toney, \& Hardeman, 2003; Verheijden et al., 2005). For example, the revision of Glenny, O'meara, Melville, Sheldon \& Wilson (1997) found that interventions involving family members seem to show some advantages in children but in adults, specifically in interventions with couples, the effectiveness cannot be fully established. In the same way, McLean, Griffin, Toney, \& Hardeman (2003) concluded that involvement of spouses in weight loss, weight control, and weight maintenance interventions tended to improve effectiveness, however, the existing studies provided limited support. On the other hand, Avenell et al. (2004) found that family therapy has been more associated with greater weight losses for up to two years when compared to individual therapy. Also, Verheijden et al. (2005) demonstrated that social support interventions on weight management show positive results. This literature review aims to review the most recent literature (from 2005 to now) in relation to family 
social support and weight loss, specifically in women. The purpose of this article is to determine the role of social support in adult women's weight loss. The following questions will be addressed: 1) Does family social support influence the processes of weight loss in women? 2) Is there a relationship between family social support and weight in women? 3) Does the participation of family members, including partners, in weight loss interventions improve weight outcomes in women?

\section{Material and method}

Search Strategy

We searched four specialist databases: PubMed, Ebsco Medline with full text, PsycINFO, and Web of Science. The electronic searches were complemented by Google Scholar using the same terms in Spanish and Portuguese too. Manual searches of bibliographies found in all articles were done. The keywords used were: "Social support"family - "weight loss"- women.

\section{Inclusion Criteria/ Exclusion Criteria}

We applied the following inclusion criteria: 1) studies should be related to at least one of the research questions; 2) they should be intervention studies or analysis of intervention studies aiming to evaluate the effectiveness of the familiar social support component in weight loss; 3) the population of the study should include adult women between 18 and 65 years old, and body weight should be an outcome measure. Studies were excluded if the population of the study included people with diabetes, cancer, pregnant or post-partum women. They were also excluded if the articles described protocols and not results and were published before 2005. The two exceptions were the article of Cousins et al (1992) and Teixeira et al (2002) because these articles were not included in the previous literature reviews.

Assessment of study quality

As Khan, Kunz, Kleijnen, \& Antes (2003) proposed, to assess the quality of the studies we developed a quality hierarchy tool (Table 1). This tool rated the studies based on certain criteria: the intervention study design, the type of the sample, the reliability and validity of the measures, and the control for confounding. The maximum possible points were 12. A high-quality study should have between 11 and 12 points, a moderate quality study between 7 and 10 points, and if a study obtained less than 6 points it was considered a low-quality study. No metaanalysis or statistical analyses were conducted.

Table 1.Tool to evaluate the quality of the studies
\begin{tabular}{|l|l|l|l|}
\hline \multicolumn{1}{|c|}{ Quality categories } & \multicolumn{1}{|c|}{ High $(3)$} & \multicolumn{1}{c|}{ Moderate (2) } & \multicolumn{1}{c|}{ Low (1) } \\
\hline Intervention Study Design & $\begin{array}{l}\text { Randomized controlled } \\
\text { Trial }\end{array}$ & Cuasi-experimental & Non-experimental \\
\hline Sample & Probability Sample & Purposeful sample & Convenience Sample \\
\hline $\begin{array}{l}\text { Reliability and Validity of the } \\
\text { Measures }\end{array}$ & $\begin{array}{l}\text { Report measures with } \\
\text { high levels of validity and } \\
\text { reliability }\end{array}$ & $\begin{array}{l}\text { Report measures with } \\
\text { moderate levels of validity } \\
\text { and reliability }\end{array}$ & $\begin{array}{l}\text { Reliability and Validity } \\
\text { measures are not } \\
\text { reported }\end{array}$ \\
\hline Control for confounding & $\begin{array}{l}\text { Randomization or } \\
\text { adjustment for at least } 3 \\
\text { confounding factors }\end{array}$ & $\begin{array}{l}\text { Adjustment for at least } \\
\text { one confounding factors }\end{array}$ & $\begin{array}{l}\text { No adjustment for } \\
\text { confounding factors }\end{array}$ \\
\hline
\end{tabular}

\section{Results}

Figure 1 depicts a flow chart with the number of articles remaining at each stage and the reasons for exclusion.

Figure 1. Flow chart of the article selection

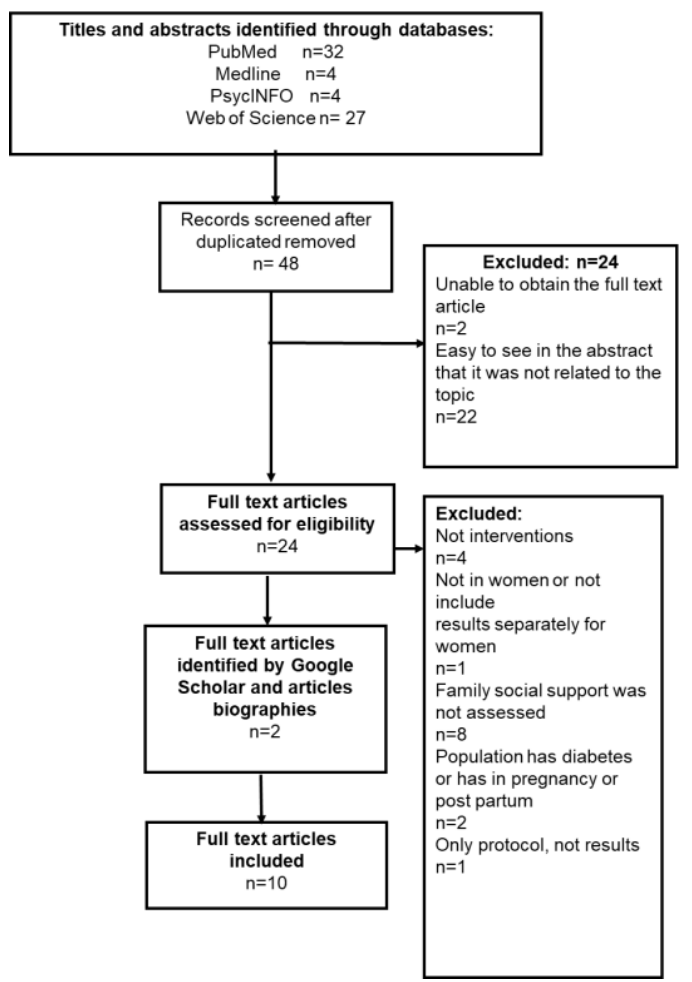


Ten papers met the selection criteria. Using our quality hierarchy tool, two papers were classified as high quality studies (Jerome et al., 2015; Johnson, Carson, Affuso, Hardy, \& Baskin, 2014), seven as medium quality studies (Cousins et al., 1992; Kiernan et al., 2012a; Kim, McEwen, Kieffer, Herman, \& Piette, 2008; Kumanyika et al., 2009; Kyryliuk, Baruth, \& Wilcox, 2015; Marquez \& Wing, 2013; Teixeira et al., 2002), and one as a low quality study (Pinelli, Brown, Herman, \& Jaber, 2011). In relation to the study design, six were randomized trials, one was a cluster randomized trial, and three had a non-experimental design. The sample sizes were between 588 and 27 individuals. All the studies were conducted in the U.S. Next, the findings will be reported for each research question.

\section{Findings and discussion}

Interventions examining the association between family social support and weight loss in women We found four studies (Jerome et al., 2015; Kiernan et al., 2012b; Kyryliuk et al., 2015; Teixeira et al., 2002) aimed to evaluate the association between family social support and weight loss in women. In three of them, the predominant population was white but also included other populations; in Kyryliuk et al., (2015) the population was African American. Three of the studies used different scales to measure different types of family social support - such as social support for diet (Jerome et al., 2015), perceived support, and sabotage from friends and family - for healthy eating and physical activity (Kiernan et al., 2012b) and general social support (Teixeira et al., 2002). One of them, Kyryliuk et al (2015), used items to evaluate social support for physical activity and consumption of fruits and vegetables. Two of them used the Sallis, Grossman, Pinski, Patterson, \& Nader (1987) scale to assess support from family and friends in relation to exercise behavior.

In three of them, family social support was not associated with weight loss: in Jerome et al (2015), family social support was not associated with weight loss either in African-American women nor nonAfrican American women. Texeira et al (2002) found that social support and social support for exercise (including family support) was not associated with weight loss either. Kyryliuk et al. (2015) did not find any association in regard to social support for physical activity (OR: $0.68,95 \%$ CI $(0.45,1.01)$ and social support for fruit and vegetable consumption (OR:0.80, 95\% CI $(0.56,1.16)$ ) and weight loss. Only the Kiernan et al (2012) study found that women who never experienced family support were least likely to lose weight ( $45.7 \%$ lost weight) while women who experienced frequent friend and family support were more likely to lose weight $(71.6 \%$ lost weight).

Interventions examining association between family social support in diet and exercise and Body Mass Index (BMI)

There are two studies that investigated the association between family social support and BMI (Johnson et al., 2014; Kim et al., 2008). Both studies used the Sallis et al. (1987) scale to measure social support for diet and exercise. Johnson et al. (2014) worked with African-American women in the rural Deep South. They showed that these women experienced minimal social support from family and friends for healthy eating and exercise. Moreover, they found also that both family and friends concurrently encouraged and discouraged healthy eating, and family members were more supportive than friends for obesity prevention behavior. The study of Kim et al., (2008) enrolled 228 women with records of gestational diabetes mellitus participating in a University-affiliated managed care plan, but that were not presented as having diabetes in the moment of the study. Self-efficacy and social support from family and friends for physical activity were associated with physical activity, as well as social support from family and friends for a healthy diet was associated with better dietary scores. However, in both studies, social support factors were not associated with BMI.

Interventions including family members and their relationship with weight loss.

We found four interventions that aimed to know if the inclusion of family members improved weight loss outcomes. Three randomized trials (Cousins et al., 1992; Kumanyika et al., 2009; Marquez \& Wing, 2013) and one with a non-experimental design (Pinelli et al., 2011), that had sample sizes between 27 and 281, were carried out in non-white women. The family social support was measured in two different ways: 1) as attendance of family members to the intervention sessions (Cousins et al., 1992; Kumanyika et al., 2009; Pinelli et al., 2011) and 2) 
through using Sallis et al (1987) Social Support for Diet and Exercise Behaviors Questionnaire (Marquez \& Wing, 2013).

In Kumanyika et al. (2009) the participants were African-American, in Cousins et al (1992) and Marquez \& Wing (2013) were Latinas, and in Pinelli et al., (2011) were Arab-Americans. Kumanika et al (2009) found that being assigned to participate with family members, friends, or other group members had no effect on weight change; enrolling with others was associated with greater weight loss only when partners participated more and lost more weight. Marquez \& Wing (2013) concluded that enlisting family or friends did not enhance weight loss outcomes in Latinas. Even Cousins et al (1992) found a trend for the family intervention to be more effective than the program for the individuals this difference was not significant in Mexican-American women. Only the study of Pinelli et al (2011) found that Arab-American women with support were significantly more likely to achieve the weight loss goal than those without support $(85 \%$ of 14 women vs $33 \%$ of 30 women, $\mathrm{p}=0.0028$ ). On the contrary, in men, even success in achieving weight loss was also higher for those with family support, although the difference was not statistically significant (44\% of 9 men vs $28 \%$ of 18 men, $p=5.42$ ).

\section{Discussion}

Despite the relevance of the worldwide increase of obesity and the theoretical importance that family social support may have in the weight loss processes, only ten studies relating family social support to weight loss in women were found in the last ten years. We found that only a few of the studies have shown an association between weight loss and family social support, and none of the studies found an association between family social support and BMI. Involving family members in weight loss programs seems to have some positive effects but the results are mixed. Thus, based on these studies, there is not enough evidence to draw solid conclusions about how family social support improves weight loss. It is important to highlight that our results do not differ from earlier reviews (Black, Gleser, \& Kooyers, 1990; McLean, Griffin, Toney, \& Hardeman, 2003; Verheijden et al., 2005; Glenny, O'meara, Melville, Sheldon \& Wilson, 1997). Although, it seems to indicate a trend in the last 10 years to use the Sallis et al (1987) Social Support and Eating Habits Survey and Social Support and Eating Habits Survey because half of the studies used them. Overall, while social support has been conceptualized in different ways and has been measured using different scales, this situation has been difficult to compare between studies. It is important to mention that none of the studies made a distinction between perceived social support and received social support. This lack of differentiation may result in an underestimation of the changes in social support because perceived social support may not change so much due to an intervention (Uchino, 2009).

More research should be carried out to inform policymakers of interventions that include the support of family members. Future research should take into consideration that the biggest challenge may be how to involve family members in interventions in a cost-effective way while taking into consideration the particularities of the family dynamic in each cultural context. For example, in Latin American countries, researchers may have a challenge to engage men in interventions due to the existing gender norms. Men may avoid certain selfcare behaviors for considering them female behaviors (Fleming \& Agnew-Brune, 2015; Montero et al., 2004). Moreover, gender differences should be taken into consideration; the characteristics of an intervention with women taking into consideration their husbands may have different characteristics than the contrary. All of these questions should be answered before carrying out interventions with women involving their family members.

\section{Limitations}

The major limitation was that only ten studies were found from 2005. Based on them, the research questions were answered Gray literature and unpublished studies were not included, and authors of the included papers were not contacted. As a result, it is possible that the findings of this review have been influenced by publication bias. Another important limitation is that the studies used different definitions and measures to evaluate family social support. Moreover, although many studies are carried out in non-white populations such as AfricanAmerican or Latino Women, all of them were implemented in the U.S. Some studies could not be included because they did not differentiate in their analysis between men and women. 


\section{Conclusions}

Given the theoretical importance of family social support in weight loss processes, it is surprising that little research has been carried out on this issue. The heterogeneity of social support definitions, the type of support evaluated, and the measurement tools that are used in the studies, limited the comparison of results among the studies and may explain the lack of solid evidence to demonstrate the importance of social support in weight loss processes.

All the articles that met the inclusion criteria were conducted in the U.S, so it is highly recommended to develop and implement more research in this important field, particularly in Latin American countries since these countries are highly familyoriented. Given that perceived support has demonstrated a greater relationship to health that received support, research may be improved by making the distinction between both types of social support. Qualitative studies in specific populations are needed to identify the best strategies to involve family members in interventions.

\section{Acknowledgments}

I want to thank Dr. Spencer Moore (Department of Health Promotion, Education, and Behavior, University of South Carolina, Columbia, South Carolina, USA) for his guide on the writing of this article

\section{References}

Avenell, A. , Broom, J. I., Brown, T. J., Poobalan, A., Aucott, L. S., Stearns, S. C., Grant, A. M. (2004). Systematic review of the long-term effects and economic consequences of treatments for obesity and implications for health improvement. Health Technology Assessment, 8 (21),1-182.

Azarbad, L., \& Gonder-Frederick, L. (2010). Obesity in Women. Psychiatric Clinics of North America. 33 (2), 423-440. doi: 10.1016/j.psc.2010.01.003

Black, D. R., Gleser, L. J., \& Kooyers, K. J. (1990). A meta-analytic evaluation of couples weight-loss programs. Health Psychology, 9(3), 330-347. doi: 10.1037/0278-6133.9.3.330

U.S. Department of Health \& Human Services. (2018). Adult Obesity Causes \& Consequences. Retrieved from https://www.cdc.gov/obesity/adult/causes.html
Cousins, J. H., Rubovits, D. S., Dunn, J. K., Reeves, R. S., Ramirez, A. G., \& Foreyt, J. P. (1992). Family versus individually oriented intervention for weight loss in Mexican American women. Public Health Reports, 107(5), 549-555.

Economic Commission for Latin America and the Caribbean. (2018). Promoting equality: An interregional perspective. Retrieved from https://www.cepal.org/en/publications/43677promoting-equality-interregional-perspective

Fleming, P. J., \& Agnew-Brune, C. (2015). Current Trends in the study of Gender Norms and Health Behaviors. Current Opinion in Psychology, 5, 72-77. doi:10.1016/j.copsyc.2015.05.001

Glenny, A.-M., O’Meara, S., Melville, A., Sheldon, T. A., \& Wilson, C. (1997). Review: The treatment and prevention of obesity: a systematic review of the literature. International Journal of Obesity, 21(9), 715. doi:10.1038/sj.ijo.0800495

Greaves, C. J., Sheppard, K. E., Abraham, C., Hardeman, W., Roden, M., Evans, P. H. (2011). Systematic review of reviews of intervention components associated with increased effectiveness in dietary and physical activity interventions. BMC Public Health, 11(1), 119. doi:10.1186/1471-2458-11-119

Jerome, G. J., Myers, V. H., Young, D. R., MatthewsEwald, M. R., Coughlin, J. W., Wingo, B. C., Brantley, P. J. (2015). Psychosocial predictors of weight loss by race and sex. Clinical Obesity, 5(6), 342-348. doi:10.1111/cob.12120

Johnson, E. R., Carson, T. L., Affuso, O., Hardy, C. M., \& Baskin, M. L. (2014). Relationship between social support and body mass index among overweight and obese African American women in the rural deep South, 2011-2013. Preventing Chronic Disease, 11, E224. doi:10.5888/pcd11.140340

Kelsey, K., Earp, J. A. L., \& Kirkley, B. G. (1997). Is Social Support Beneficial for Dietary Change? A Review of the Literature. Family \& Community Health, 20(3), 70.

Khan, K. S., Kunz, R., Kleijnen, J., \& Antes, G. (2003). Five steps to conducting a systematic review. Journal of the Royal Society of Medicine, 96(3), 118-121.

Kiernan, M., Moore, S. D., Schoffman, D. E., Lee, K., King, A. C., Taylor, C. B., Perri, M. G. (2012a). Social support for healthy behaviors: Scale psychometrics and prediction of weight loss among women in a behavioral 
program. Silver Spring, Md., 20(4), 756-764. doi:10.1038/oby.2011.293

Kim, C., McEwen, L. N., Kieffer, E. C., Herman, W. H., \& Piette, J. D. (2008). Self-efficacy, social support, and associations with physical activity and body mass index among women with histories of gestational diabetes mellitus. The Diabetes Educator, 34(4), 719728. doi:10.1177/0145721708321005

Kumanyika, S. K., Wadden, T. A., Shults, J., Fassbender, J. E., Brown, S. D., Bowman, M. A., Wu, X. (2009). Trial of family and friend support for weight loss in African American adults. Archives of Internal Medicine, 169(19), 1795-1804. doi:10.1001/archinternmed.2009.337

Kyryliuk, R., Baruth, M., \& Wilcox, S. (2015). Predictors of Weight Loss for African-American Women in the Faith, Activity, and Nutrition (FAN) Study. Journal of Physical Activity \& Health, 12(5), 659-665. doi:10.1123/jpah.2013-0220

Luppino, F. S., de Wit, L. M., Bouvy, P. F., Stijnen, T., Cuijpers, P., Penninx, B. W. J. H., \& Zitman, F. G. (2010). Overweight, obesity, and depression: A systematic review and meta-analysis of longitudinal studies. Archives of General Psychiatry, 67(3), 220 229. doi:10.1001/archgenpsychiatry.2010.2

Marquez, B., \& Wing, R. R. (2013). Feasibility of Enlisting Social Network Members to Promote Weight Loss among Latinas. Journal of the Academy of Nutrition and Dietetics, 113(5), 680-687. doi:10.1016/j.jand.2013.01.020

Martinez-Jaikel, T., \& Frongillo, E. (2016). Primary role of discouragement in co- existence of food insecurity and excess weight in Costa Rican women. Journal of Hunger and Environmental Nutrition, 11(2), 1-17. doi:10.1080/19320248.2016.1157546

McLean, N., Griffin, S., Toney, K., \& Hardeman, W. (2003). Family involvement in weight control, weight maintenance and weight-loss interventions: A systematic review of randomised trials. International Journal of Obesity, 27(9), 987-1005. doi:10.1038/sj.ijo.0802383

Montero, I., Aparicio, D., Gómez-Beneyto, M., MorenoKüstner, B., Reneses, B., Usall, J., \& VázquezBarquero, J. L. (2004). Género y salud mental en un mundo cambiante. Gaceta Sanitaria, 18(S1), 175-181.

National Institute of Diabetes and Digestive and Kidney Diseases. (2012). Overweight and Obesity Statistics. Retrieved from http://www.niddk.nih.gov/health-
information/health-statistics/Pages/overweightobesity-statistics.aspx

NHLBI Obesity Education Initiative Expert Panel. (1998). Clinical Guidelines on the Identification, Evaluation, and Treatment of Overweight and Obesity in Adults. Retrieved from https://www.ncbi.nlm.nih.gov/books/NBK2003/

Pinelli, N. R., Brown, M. B., Herman, W. H., \& Jaber, L. A. (2011). Family support is associated with success in achieving weight loss in a group lifestyle intervention for diabetes prevention in Arab Americans. Ethnicity \& Disease, 21(4), 480-484.

Sallis, J. F., Grossman, R. M., Pinski, R. B., Patterson, T. L., \& Nader, P. R. (1987). The development of scales to measure social support for diet and exercise behaviors. Preventive Medicine, 16(6), 825-836. doi:.1016/0091-7435(87)90022-3

Secretaría de Salud. (2017). Encuesta Nacional de Salud y Nutrición de Medio Camino 2016. Retrieved from http://www.gob.mx/salud/documentos/encuestanacional-de-salud-y-nutricion-de-medio-camino-2016

Teixeira, P. J., Going, S. B., Houtkooper, L. B., Cussler, E. C., Martin, C. J., Metcalfe, L. L., Lohman, T. G. (2002). Weight Loss Readiness in Middle-Aged Women: Psychosocial Predictors of Success for Behavioral Weight Reduction. Journal of Behavioral Medicine, 25(6), 499-523. doi:10.1023/A:1020687832448

Thoits, P. A. (2011). Mechanisms Linking Social Ties and Support to Physical and Mental Health. Journal of Health and Social Behavior, 52(2), 145-161. doi:10.1177/0022146510395592

Uchino, B. N. (2009). Understanding the Links Between Social Support and Physical Health: A Life-Span Perspective With Emphasis on the Separability of Perceived and Received Support. Perspectives on Psychological Science, 4(3), 236-255. doi:10.1111/j.1745-6924.2009.01122.x

Verheijden, M. W., Bakx, J. C., van Weel, C., Koelen, M. A., \& van Staveren, W. A. (2005). Role of social support in lifestyle-focused weight management interventions. European Journal of Clinical Nutrition, 59 (1), S179-186. doi:10.1038/sj.ejcn.1602194

World Health Organization. (2015). Obesity and overweight. Retrieved from http://www.who.int/mediacentre/factsheets/fs311/en/ 